\title{
A Global Analysis of Land Surface Temperature Diurnal Cycle Using MODIS Observations
}

\author{
ZAHRA SHARIFNEZHADAZIZI \\ City College of New York, City University of New York, New York, New York
}

\section{HAMID NOROUZI}

New York City College of Technology, City University of New York, Brooklyn, and Earth and Environmental Sciences, Graduate Center, City University of New York, New York, New York

\section{SATYA PRAKASH}

Divecha Centre for Climate Change, Indian Institute of Science, Bengaluru, India

\section{CHRISTOPHER BEALE}

New York City College of Technology, City University of New York, Brooklyn, New York

REZA KHANBILVARDI

City College of New York, City University of New York, New York, New York

(Manuscript received 27 September 2018, in final form 28 March 2019)

\begin{abstract}
Diurnal variations of land surface temperature (LST) play a vital role in a wide range of applications such as climate change assessment, land-atmosphere interactions, and heat-related health issues in urban regions. This study uses 15 years (2003-17) of daily observations of LST Collection 6 from the Moderate Resolution Imaging Spectroradiometer (MODIS) instruments on board the Aqua and the Terra satellites. A spline interpolation method is used to estimate half-hourly global LST from the MODIS measurements. A preliminary assessment of interpolated LST with hourly ground-based observations over selected stations of North America shows bias and an error of less than $1 \mathrm{~K}$. Results suggest that the present interpolation method is capable of capturing the diurnal variations of LST reasonably well for different land-cover types. The diurnal cycle of LST and time of occurrence of maximum temperature are computed from the spatially and temporally consistent interpolated diurnal LST data at a global scale. Regions with higher variability in the timing of maximum LST hours and diurnal amplitude are identified in this study. The global desert regions show generally small variability of the monthly mean diurnal LST range, whereas larger areas of the global land exhibit rather higher variability in the diurnal LST range during the study period. Moreover, the changes in diurnal temperature range for the study period are examined for distinct land-cover types. Analysis of the 15 -yr time series of the diurnal LST record shows an overall decrease of $0.5 \mathrm{~K}$ in amplitude over the Northern Hemisphere. However, the diurnal LST range shows variant changes in the Southern Hemisphere.
\end{abstract}

\section{Introduction}

Reliable estimates of land surface temperature (LST) and its diurnal variations are vital for the adequate understanding of surface energy budget and land-atmosphere interactions, for the detection of forest fires, urban heat

Corresponding author: Hamid Norouzi, hnorouzi@citytech.cuny.edu island monitoring, evaluation of land surface models, and assessment of climate change (Braganza et al. 2004; Tomlinson et al. 2011; Li et al. 2013; Zhan et al. 2013; Thorne et al. 2016). LST has been considered as one of the high-priority parameters of the International GeosphereBiosphere Programme. The solar insolation, atmospheric state, and land surface characteristics (e.g., vegetation cover, soil moisture, land-cover type) regulates the diurnal 
cycle of LST (Ignatov and Gutman 1999; Duan et al. 2014a). The diurnal cycle of skin temperature over the ocean is essentially different from that over the land. Moreover, the diurnal cycle patterns of LST vary locally with season and land-cover type, and are different in magnitudes from those of near-surface air temperature and upper-layer soil temperature (Norouzi et al. 2012; Prakash et al. 2017, 2019; Shati et al. 2018).

Ground-based observations of LST are generally sparse at global scale and hence appear to be inadequate to study its variability at larger spatial scale. However, satellite remote sensing provides an effective way to measure LST uniformly at global scale (Tomlinson et al. 2011; Li et al. 2013). LST is measured from broadly two types of Earthobservation satellite sensors: (i) thermal infrared sensors and (ii) microwave sensors. The LST derived from the thermal infrared measurements has higher spatial resolution and retrieval accuracy. However, infrared-based measurements are restricted to clear-sky conditions only and obscured by presence of clouds and atmospheric disturbances. Although passive microwave measurements essentially provide LST estimates for all weather conditions, they suffer from rather coarser spatial and temporal resolutions. Moreover, uncertainty in the passive microwave retrieved LST during precipitation has shown to be rather larger than infrared-based estimates. The synergistic use of infrared and microwave measurements has been recommended for the optimal estimation of LST for all weather conditions (Li et al. 2013; Duan et al. 2017).

The thermal infrared-based LST estimates from the polar-orbiting satellites have received more attention in last two decades for several global and local applications. For instance, LST estimates from the Moderate Resolution Imaging Spectroradiometer (MODIS) sensors have been used for urban heat island detection, assessment of land surface changes, evaluation of land surface model outputs, land and atmospheric parameters retrieval, and several other applications (Wan 2014; Norouzi et al. 2015; Prakash et al. 2016, 2018; Didari et al. 2017; Mildrexler et al. 2018). However, MODIS sensors are unable to provide complete global coverage of diurnal LST estimates, and a spatiotemporal interpolation is required to study the global LST variability. Several interpolation methods have been reported in literature for satellite remote sensing data including infrared-based LST (Aires et al. 2004; Duan et al. 2014a; Norouzi et al. 2012; Zhou et al. 2013; Weng and Fu 2014; Ruzmaikin et al. 2017). Aires et al. (2004) analyzed and constructed the diurnal cycle of infrared-based LST using a principal component analysis at a quasi-global scale using the International Satellite Cloud Climatology Project (ISCCP) skin temperature product (Rossow and Schiffer 1999). Duan et al. (2014a) used a semiempirical diurnal temperature cycle model to construct the diurnal cycle of MODIS-derived LST over the Mediterranean region. Zhou et al. (2013) utilized a diurnal temperature cycle genetic algorithm with multisource satellite data to generate hourly LST at 1-km spatial resolution for the study of diurnal variations of urban heat islands in China. Weng and Fu (2014) developed a support vector machine method for downscaling coarse-resolution infrared LST into finer spatiotemporal resolution for monitoring of surface urban heat islands in the Los Angeles region.

Ruzmaikin et al. (2017) examined the changes in spatial patterns of diurnal temperature range (DTR) from the skin temperature measurements of the Atmospheric Infrared Sounder (AIRS) sensor on board the Aqua satellite using empirical mode decomposition. They noticed an increase of about $0.2 \mathrm{~K}$ in the global DTR between 2002 and 2015 that is possibly due to decrease in nighttime low cloud fraction. However, DTR was found to be nonmonotonic over the oceanic regions and in the extremely hot areas of Earth. The spatial resolution of the AIRS is rather coarser $(\sim 100 \mathrm{~km})$ than the MODIS sensor. Additionally, MODIS sensors are mounted on both Aqua and Terra satellites and provide generally four observations daily at a given location, which may help to accurately estimate LST diurnal variations. Recently, Prakash et al. (2019) comprehensively assessed the differences between MODIS- and AIRS-derived clear-sky LST estimates over the global land areas. They also showed that LST exhibits stronger diurnal variability than the surface air temperature.

The objective of this study is twofold: 1) to generate spatially consistent global maps of subdaily LST from the MODIS measurements under clear-sky condition and 2) to assess the variability of DTR for different vegetation types at global scale for the 15-yr period of 2003-17. Section 2 describes the datasets used in this study, and the method for the computation of diurnal cycle of LST is presented in section 3. Results are presented and discussed in section 4, and conclusions are outlined in section 5 .

\section{Data used}

\section{a. Land surface temperature data}

The MODIS sensors on board the Aqua and Terra satellites measure high-spatial-resolution atmospheric, oceanic, and land surface parameters at 36 visible and infrared channels with a wide spectral range of 0.4$14.4 \mu \mathrm{m}$ (Justice et al. 1998). These two sun-synchronous satellites are polar orbiting and provide global coverage in nearly two days. The Terra satellite crosses the equator from north to south at about 1030 local time, whereas the Aqua satellite crosses the equator from 
south to north at about 1330 local time. These satellites take measurements twice a day (e.g., ascending and descending orbits) at a specific location. The MODIS products from the Terra and the Aqua satellites are available since March 2000 and July 2002, respectively. The cloud-free daily global LST products (e.g., MOD11C1 from the Terra and MYD11C1 from the Aqua satellites) Collection 6 (Wan 2014) available at a $0.05^{\circ}$ (about $5 \mathrm{~km}$ at the equator) climate modeling grid were obtained from the Land Processes Distributed Active Archive Center (LP DAAC). Collection 6 LST products incorporate improvements in retrieval algorithms and proven to be more accurate than its predecessor Collection 5 LST products (Wan 2014; Duan et al. 2018). The differences between Collection 6 and Collection 5 products were remarkable over the arid regions (Prakash et al. 2018). Moreover, the accuracy of Collection 6 LST products was found to be approximately 2 times better than those of Collection 5 products over bare soil areas, when validated using the radiance-based method (Duan et al. 2018). The combination of ascending and descending overpasses of both MODIS sensors provides generally four measurements of LST at a specific grid each day at about 0130, 1030, 1330, and 2230 local times. The global LST products for a 15 -yr period (e.g., January 2003-December 2017) were considered in this study.

For the preliminary evaluation of diurnal cycle of LST derived from the MODIS products, ground-based observations of LST from the U.S. Climate Reference Network (USCRN) were used. The USCRN is an automated network of more than 140 stations designed to provide high-quality continuous observations of climate variables (Bell et al. 2013; Diamond et al. 2013). Hourly LST observations from 18 selected stations for the year 2017 were used in this study.

\section{b. Land-cover type data}

A global static classification of 10 vegetation types (Prigent et al. 1998; Norouzi et al. 2015) derived from 32 different land-cover types (Matthews 1983) has been used in this study. The name of each vegetation class and their percentage coverage over the global land area are tabulated in Table 1. The wooded and nonwooded grassland covers about $23 \%$ of global land, whereas nonvegetated desert covers about $11 \%$ of the global land area. It is to be noted that the diurnal cycle patterns of LST significantly influenced by the land-cover types (Scheitlin and Dixon 2010; Norouzi et al. 2012; Prakash et al. 2019).

\section{Computation of diurnal cycle of LST}

To characterize the diurnal cycle of global LST under clear-sky conditions, the MODIS-derived LST data were
TABLE 1. Land-cover types used in this study and their percentage coverage over the global land.

\begin{tabular}{llc}
\hline \hline Code & \multicolumn{1}{c}{ Vegetation type } & $\begin{array}{c}\text { Percentage } \\
\text { coverage }\end{array}$ \\
\hline LC01 & $\begin{array}{c}\text { Tropical/subtropical evergreen } \\
\text { broadleaf forest }\end{array}$ & 8.00 \\
LC02 & Deciduous forest \\
LC03 & $\begin{array}{l}\text { Evergreen broadleaf and } \\
\text { needleleaf forest }\end{array}$ & 11.12 \\
LC04 & $\begin{array}{l}\text { Deciduous woodland } \\
\text { LC05 }\end{array}$ & $\begin{array}{c}\text { Sclerophyllous woodland and } \\
\text { forest }\end{array}$ \\
LC06 & $\begin{array}{l}\text { Wooded and nonwooded } \\
\text { grassland }\end{array}$ & 9.48 \\
LC07 & Tundra and mossy bog \\
LC08 & $\begin{array}{c}\text { Boreal and xeromorphic } \\
\text { shrubland }\end{array}$ & 5.10 \\
LC09 & Nonvegetated desert & 3.18 \\
LC10 & Ice & 23.31 \\
\hline
\end{tabular}

reprojected to an equal-area grid (equivalent to $0.25^{\circ}$ at equator) and land-only pixels were extracted for computational efficiency. LST products from the MODIS are often influenced by clouds and other atmospheric disturbances, which resulted in remarkable data loss. Several techniques have been developed so far to compute equivalent LST values at the missing grids of the MODIS swath. But, most of these techniques are suitable for rather smaller regions and fail at the global scale (Kilibarda et al. 2014; Yu et al. 2015). In addition, geostatistical interpolation methods basically depend on the values of neighboring grids; hence, they are not effective for a larger area having missing values. As a longer time series (e.g., 15 years) of LST is being considered in this study, a statistical method based on temporal variations was utilized for filling the data gap at different time of the day. The goal of present study is to analyze the global diurnal cycle of LST when observations from clear-sky conditions are utilized.

Based on previous studies (Norouzi et al. 2015), it is reasonable to assume that general characteristics of LST diurnal variations such as amplitude and timing of maximum temperature do not change significantly in a month. Figure 1 depicts the schematic estimation process of missing observation data. If at a given grid, there are one, two or three unavailable LST values, they are computed by differences between the available values of that date and the monthly average of the same time of the day. For instance, only two daily Aqua data points (taken at 0130 and 1330 local time) are available in Fig. 1. The differences of those two points and the corresponding monthly average of the same time of the day are first calculated followed by taking the average of their values. In the next step, the average value calculated in the latter phase is added to the monthly average 


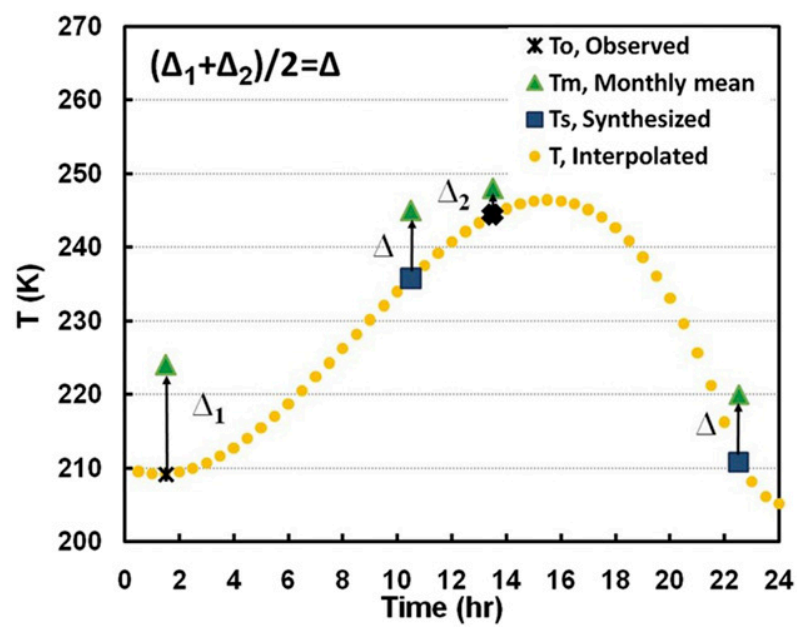

FIG. 1. Schematic for unavailable data estimation process based on the difference of monthly mean LST $T_{m}$ and observed LST $T_{o}$ at each of daily observation time; $\Delta_{1}=T_{m}-T_{o}(0130$ local time $)$ and $\Delta_{2}=T_{m}-T_{o}$ (1330 local time) for a day with only two observations available.

of the unavailable daily data. On the other hand, if there are missing values at all four times each day, the corresponding pixel and day is not included in our analysis.

Finally, an interpolation method needs to be applied with the synthesized data to construct the LST diurnal cycle. A spline interpolation method had been successfully utilized to study the diurnal variations of infrared LST and passive microwave brightness temperatures (Aires et al. 2004; Norouzi et al. 2012). The spline interpolation method showed smooth diurnal variation of LST and there was no need for best-fit to capture minimum and maximum values between two consecutive observations. Therefore, spline piecewise polynomial interpolation has been used in this study to render halfhourly LST from the MODIS products. Since four observations of LST might not be enough as control points for obtaining a reliable daily interpolation, the corresponding data for a series of three consecutive days (one day before and one day after) with 12 control points were considered for the construction of half-hourly diurnal cycle. Figure 2 presents the diurnal variations of LST at four locations having distinct vegetation types using original MODIS products and from interpolated half-hourly LST values for February 2017. In each plot of the figure, available daily observations from the original MODIS products (red star), the monthly mean LST (green triangle), synthesized LST (blue circle), and interpolated LST (pink dot) based on synthesized data are shown. Missing data from the MODIS observations can be encountered in four different ways that are also illustrated in Fig. 2. The general diurnal patterns of LST and their variations with distinct land-cover types (Prakash et al. 2019) are well-depicted by the interpolated LST.
From 2003 to 2017, approximately 31\% of global land area has missing data in the MODIS-derived LST products. Even after generation of synthesized data, there are still few missing points (about 1.1\%) having all-time cloud contamination for a month that cannot be replaced by monthly average. The results from the cases that all observations in a day are missing (such as Fig. 2d) are not included in studying LST diurnal variations in following steps. The 15-yr missing data ratio of two contrasting months (January-July) is 1.1, which states that the number of missing grids is generally larger during the northern winter season than the northern summer season.

\section{Results and discussion}

\section{a. Evaluation of interpolated diurnal cycle of LST}

To assess the accuracy of the proposed method, a preliminary evaluation between MODIS-derived LST diurnal cycle and ground-based observations has been performed for the year 2017. Hourly LST observations from 18 selected USCRN stations across the North America have been considered. Table 2 presents the location, elevation, and land-cover type of the selected USCRN stations. These stations are selected in such a way that they cover a wide range of elevations and three distinct vegetation types. Figures $3 \mathrm{a}$ and $3 \mathrm{~b}$ illustrate the comparison of hourly LST from the present method and USCRN observations for the entire year of 2017 for two stations: Charlottesville, Virginia, and Des Moines, Iowa. Hourly LST from MODIS is computed from the interpolated half-hourly LST estimates. Higher correlations of 0.84 and 0.86 and lower rootmean-square errors (RMSE) of 0.25 and $0.15 \mathrm{~K}$ between both LSTs for Charlottesville and Des Moines stations, respectively, suggest reasonably good performance of the interpolated LST. The reason for having smaller RMSE than bias is that to account for systematic biases between ground-based and satellite measurements, we used "bias" as an indicator. However, to account for only random differences, we calculated the RMSE values after the removal of bias estimates. The primary objective of this study is to interpolate diurnal variations of LST from the satellite estimates. So, we removed the bias in order to compute RMSE to just see the random variations in LST diurnally. The mean diurnal cycles of LST for the two contrasting months of January and July from the present method and USCRN observations for these two stations are shown in Figs. $3 \mathrm{c}$ and $3 \mathrm{~d}$. The patterns of diurnal cycle of LST are similar for both months from both datasets. However, there is an underestimation of diurnal cycle magnitude by the present method as compared to the USCRN observations.

Figure 4a shows the scatterplot between hourly LST estimates from the present method and USCRN 

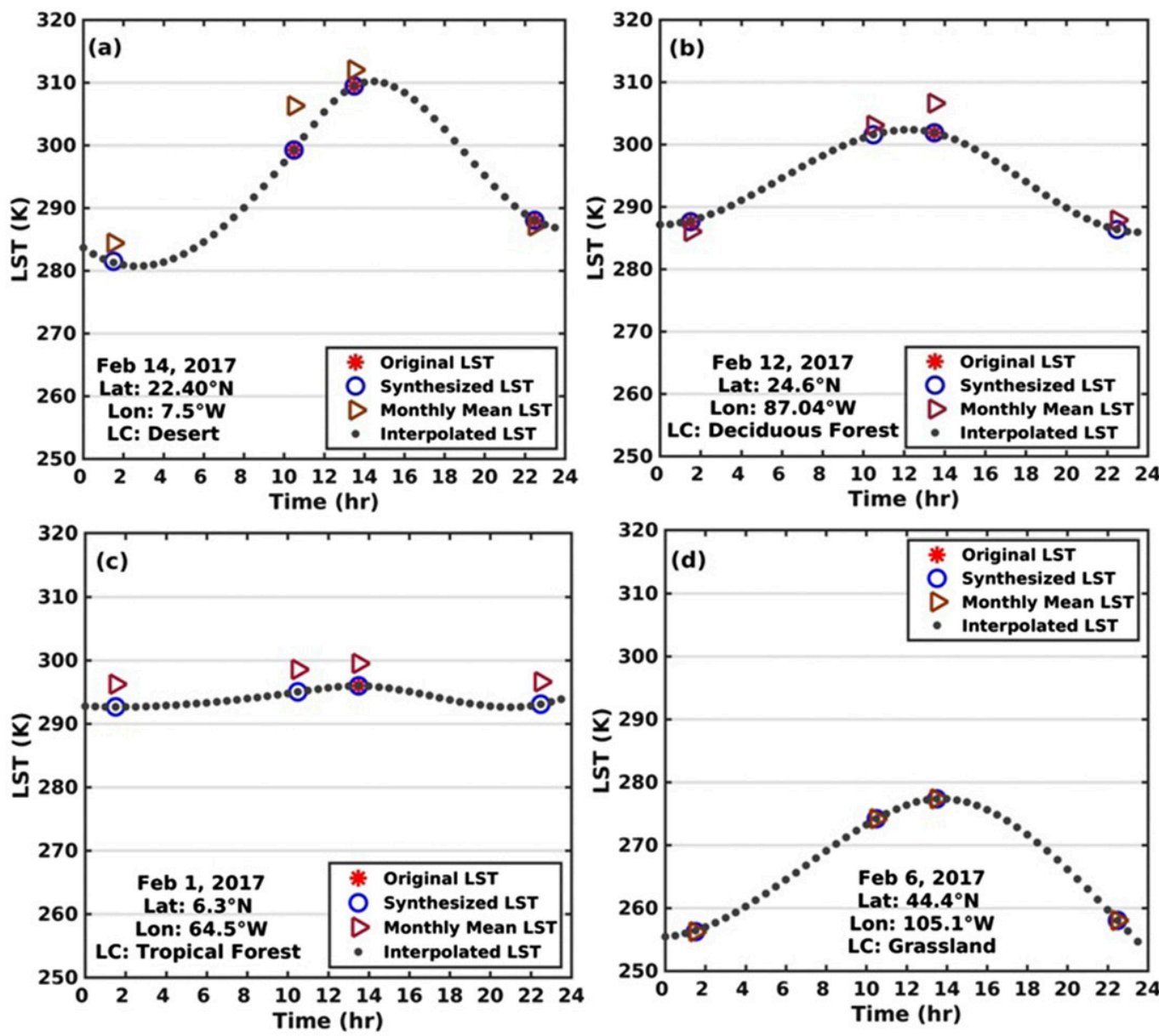

FIG. 2. Diurnal variations of interpolated LST for four sample locations with different data availability and for distinct land cover. The original MODIS-derived LST, synthesized LST, and monthly mean LST are also shown.

observations for all selected stations. There is a good agreement (linear correlation of 0.86 ) between both LST estimates can be seen for the year 2017. The bias and RMSE (after bias removal) are appreciably less than $1 \mathrm{~K}$, revealing that the present model is capable in capturing the diurnal variations of LST reasonably well for different land-cover types. The agreement between both LST estimates is rather weaker around $273 \mathrm{~K}$, corresponding to freeze-thaw transitions. LST from the present model underestimates during these periods as compared to the USCRN observations. A cold bias in MODIS LST is expected during the freezing time periods probably because of the overrepresentation of clear-sky conditions (Muster et al. 2015). Figure 4b presents the diurnal cycle of correlation and RMSE combined for all selected stations. The quality of the interpolated LST is not consistent throughout the day, and error characteristics vary with time. The differences of LST between MODIS and USCRN could be primarily attributed to the facts that these two estimates capture the temperature at different spatial resolutions. The satellite measures area-averaged LST, while the USCRN stations provide point observations representing localized LST. Furthermore, the MODIS sensor records LST above the tree canopies over forest areas (Li et al. 2013; Zhan et al. 2013), while the USCRN stations record data at the surface. The USCRN provides LST observations for all weather conditions, whereas the interpolated LST has been derived from clear-sky condition LST alone. These factors might be intermittently contributing the discrepancies between both LST estimates.

\section{b. Spatial distributions of global land DTR and timing of daily maximum LST}

DTR is defined as the difference between daily maximum and minimum surface air temperature and is proven to be a better indicator of climate change and variability (Braganza et al. 2004; Thorne et al. 2016). The diurnal cycle of LST enables the computation of magnitudes and time of occurrence of daily maximum 
TABLE 2. Location, elevation, and land-cover types of U.S. Climate Reference Network (USCRN) stations used for evaluation of MODIS-derived hourly land surface temperatures.

\begin{tabular}{|c|c|c|c|c|c|}
\hline Station No. & Station name & Lat $\left(^{\circ}\right)$ & Lon $\left(^{\circ}\right)$ & Elevation (m) & LC type \\
\hline 1 & Lafayette, Louisiana & 30.09 & -91.87 & 11 & $\mathrm{LC} 02$ \\
\hline 2 & Selma, Alabama & 32.46 & -87.24 & 63 & \\
\hline 3 & Blackville, South Carolina & 33.36 & -81.33 & 99 & \\
\hline 4 & Millbrook, New York & 41.79 & -73.74 & 142 & \\
\hline 5 & Charlottesville, Virginia & 38.00 & -78.47 & 206 & \\
\hline 6 & Watkinsville, Georgia & 33.78 & -83.39 & 218 & \\
\hline 7 & Limestone, Maine & 46.96 & -67.88 & 239 & \\
\hline 8 & Des Moines, Iowa & 41.56 & -93.29 & 261 & \\
\hline 9 & Crossville, Tennessee & 36.01 & -85.13 & 578 & \\
\hline 10 & Merced, California & 37.24 & -120.88 & 24 & $\mathrm{LC} 03$ \\
\hline 11 & Darrington, Washington & 48.54 & -121.45 & 110 & \\
\hline 12 & Sebring, Florida & 27.15 & -81.37 & 46 & $\mathrm{LC} 06$ \\
\hline 13 & Chillicothe, Missouri & 39.87 & -93.15 & 255 & \\
\hline 14 & Manhattan, Kansas & 39.10 & -96.61 & 357 & \\
\hline 15 & Aberdeen, South Dakota & 45.71 & -99.13 & 597 & \\
\hline 16 & Wolf Point, Montana & 48.31 & -105.10 & 632 & \\
\hline 17 & Monahans, Texas & 31.62 & -102.81 & 828 & \\
\hline 18 & Williams, Arizona & 35.76 & -112.34 & 1821 & \\
\hline
\end{tabular}

and minimum LSTs. The difference in daily maximum and minimum LST estimates is termed DTR hereafter in this study. Figures $5 \mathrm{a}$ and $5 \mathrm{~b}$ illustrate the global monthly mean DTR derived from the interpolated halfhourly LST for the two contrasting months of January and July 2017. Larger DTR during the summer than winter is evident in both hemispheres. The largest magnitudes of DTR $(25-40 \mathrm{~K})$ are evident in primarily two land-cover types-nonvegetated deserts, and Boreal and xeromorphic shrublands with low vegetation density. For instance, DTR is consistently large over the Northern Hemispheric regions of Great Basin of Nevada, Colorado Plateau, the Sahara in North Africa, Saudi Arabia, and the Gobi Desert in China and Mongolia. In the Southern Hemisphere, the Kalahari Desert in the southern Africa, shrublands of the Andes Mountains in South America, and Australian deserts are three regions with higher DTR. As land surface warms and cools rapidly, the absence or lack of vegetation and moisture across the desert regions make DTR larger than other regions of Earth. The lowest DTR of less than $5 \mathrm{~K}$ can be found in two main areas: tropical rain forests and high-latitude regions of Russia (Siberia) and Greenland. In the northern high latitudes, ice and snow cover cool the surface air and act as insulators to the solar radiation, which maintain rather smaller DTR. It can also be seen that DTR is essentially larger over the high-latitude regions during the northern summer than the winter. In general, the maps of DTR pose a systematic relation with land-cover type. Land-cover type is one of the most important parameters to influence the global LST change (Duveiller et al. 2018; Song et al.
2018). A close association of vegetation type with nearsurface air temperature diurnal cycle was also reported in earlier studies (Lim et al. 2008; Jackson and Forster 2010; Scheitlin and Dixon 2010).

Figures $5 \mathrm{c}$ and $5 \mathrm{~d}$ present the spatial distributions of standard deviation in DTR for January and July 2017. The tropical vegetated areas such as tropical rain forests show generally small standard deviation of DTR $(<3 \mathrm{~K})$. A larger standard deviation in DTR of more than $5 \mathrm{~K}$ can be seen over the high-latitude regions that is more pronounced during the northern winter. Highlatitude regions eventually receive snowfall during the northern winter season, which substantially affects the DTR variability. A similar seasonal and locationspecific variation in DTR of surface air over land due to combined effect of solar radiation, elevation, cloud cover, precipitation, and soil moisture was also reported by Jackson and Forster (2010).

Figure 6 illustrates the spatial distributions of normalized standard deviation of monthly mean DTR for a 15 -yr period. It is computed by normalizing the standard deviation of monthly mean DTR with respect to the 15-yr mean DTR. The global desert regions show exceptionally small variability of DTR $(<15 \%)$ for the study period. However, larger areas of the global land exhibit larger variability in DTR ranging from $20 \%$ to $40 \%$ for the study period. This larger variability in DTR might be associated with changes in the state of the atmosphere, albedo, moisture, land emissivity, and land surface properties (Duan et al. 2014a). The gradual changes in vegetation cover are vital for DTR variability. For instance, the expansion of agricultural land in the tropical 

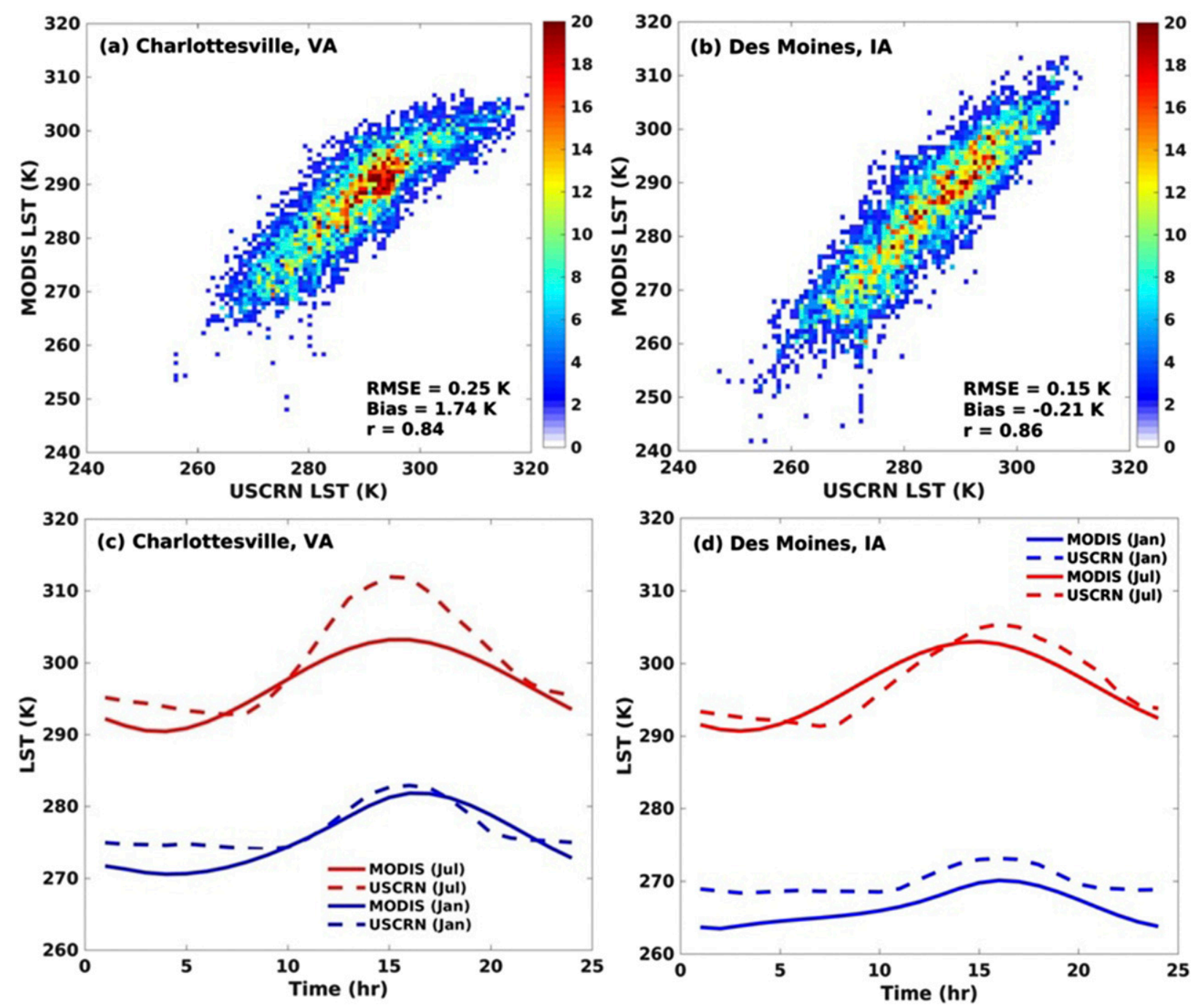

FIG. 3. Comparison between MODIS and USCRN hourly LST for 2017. (top) Scatterplots for hourly LST at (a) Charlottesville, VA, and (b) Des Moines, IA. Correlation coefficient $r$, bias, and root-mean-square errors (after bias removal) are also provided. (bottom) Mean diurnal variation for LST at (c) Charlottesville and (d) Des Moines for the two contrasting months of January and July.

regions enhanced the surface albedo and hence, considerably alters the local LST through radiative properties of Earth's energy balance (Duveiller et al. 2018). The influence of changes in vegetation cover along with air pollutant on the global LST has also been studied recently by Song et al. (2018). The impact of solar radiation, soil moisture, vegetation cover, and other parameters on DTR was also assessed through the surface energy budget by Jackson and Forster (2010), and it was noticed that surface net longwave radiation explains about $95 \%$ of the seasonal variation of DTR in the tropical regions.

The occurrence time of the daily maximum LST is also investigated in this study. The occurrence time of daily maximum LST for each pixel was computed from 48 half-hourly interpolated LST values. The spatial distributions of the monthly mean daily maximum LST hour are presented in Fig. 7 for two contrasting months, January and July 2017. Comparison of these two maps reveals a tangible seasonal variation. For the Northern Hemisphere, with changing seasons from winter to summer, timing of maximum hour moves, generally, from around 1330 to around 1230 local time. Similar characteristics with different time variation range can be seen in the Southern Hemisphere. Furthermore, it can be inferred that the time of maximum daily LST depends mainly on the latitude. However, higher latitudes, especially the Arctic regions, are subjected to some 

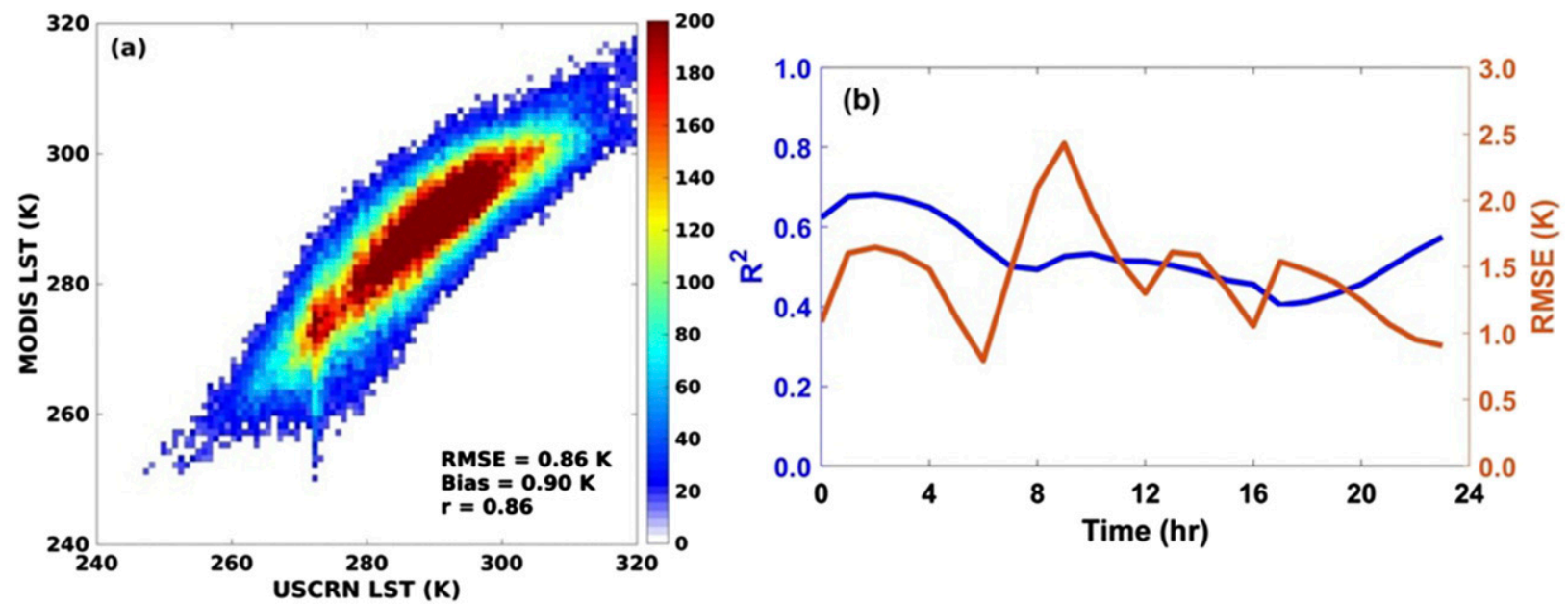

FIG. 4. Comparison between MODIS and USCRN data in 2017 for all 18 selected stations. (a) Scatterplot for hourly LST. Correlation coefficient $r$, bias, and root-mean-square errors are also provided. (b) Diurnal analysis of coefficient of determination $R^{2}$ and root-meansquare error using combined data for 18 stations. RMSE values were computed after bias removal.

inconsistencies. The observed inconsistencies can be attributed to the snow cover emissivity, which accelerates the reflection of heat energy rather than keeping it on the surface skin. This point can be seen more clearly in Fig. 8, which illustrates the 15-yr average of maximum LST hour standard deviation. The higher standard deviation over that region might be because of inaccuracy in diurnal estimation. Since the diurnal temperature changes in those areas are low, spline interpolation method may not be able to estimate the timing of maximum daily temperature accurately.

\section{c. Assessment of changes in global land DTR and timing of daily maximum LST}

Review and analysis of the average LST for the years 2003-17 may reveal the causes of seasonal differences between land cover. Thus, $15-y r$ monthly mean of DTR and timing of maximum LST for each hemisphere are
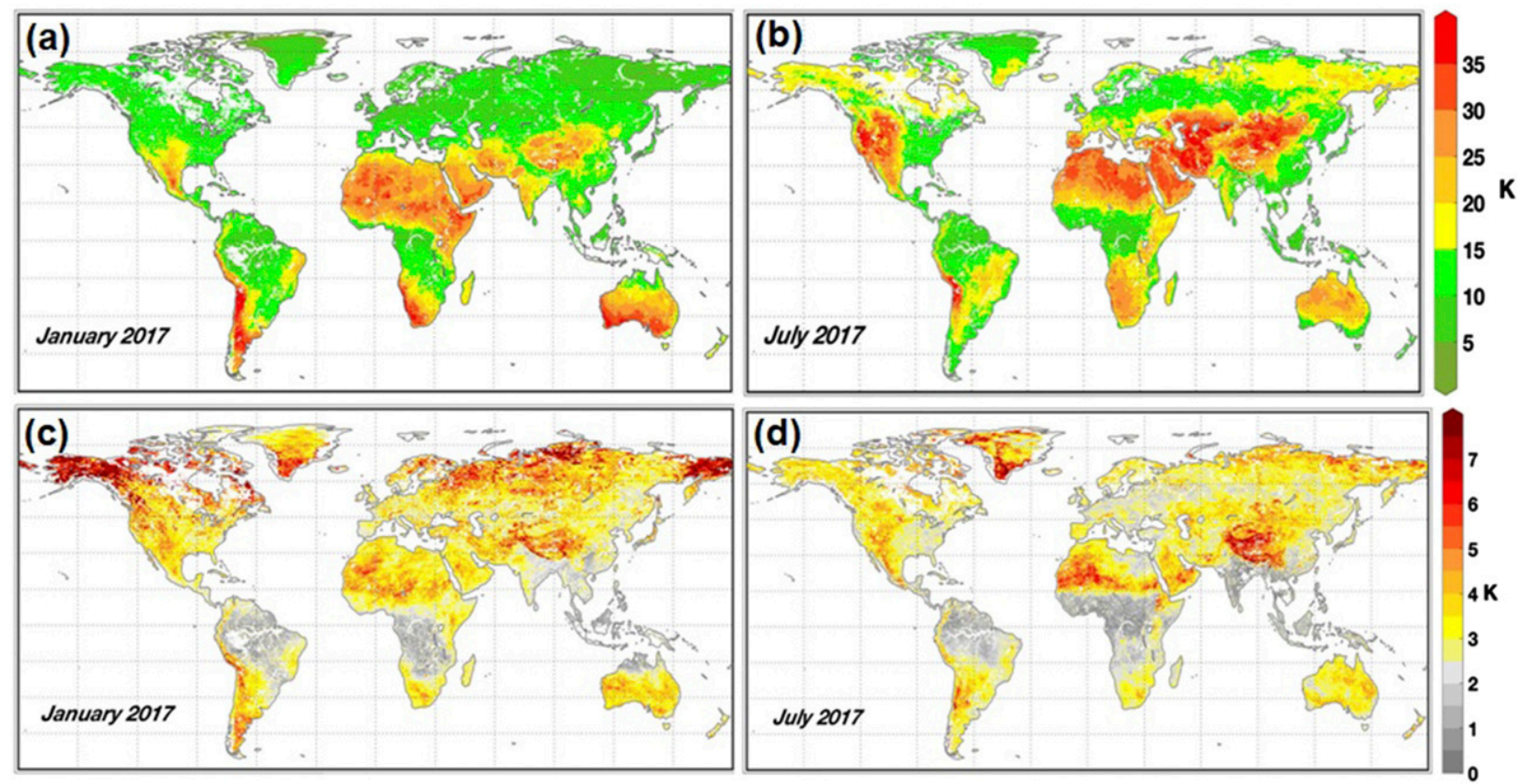

FIG. 5. Spatial distributions of (a),(b) monthly mean DTR and (c),(d) its standard deviation for (a),(c) January and (b),(d) July 2017. 


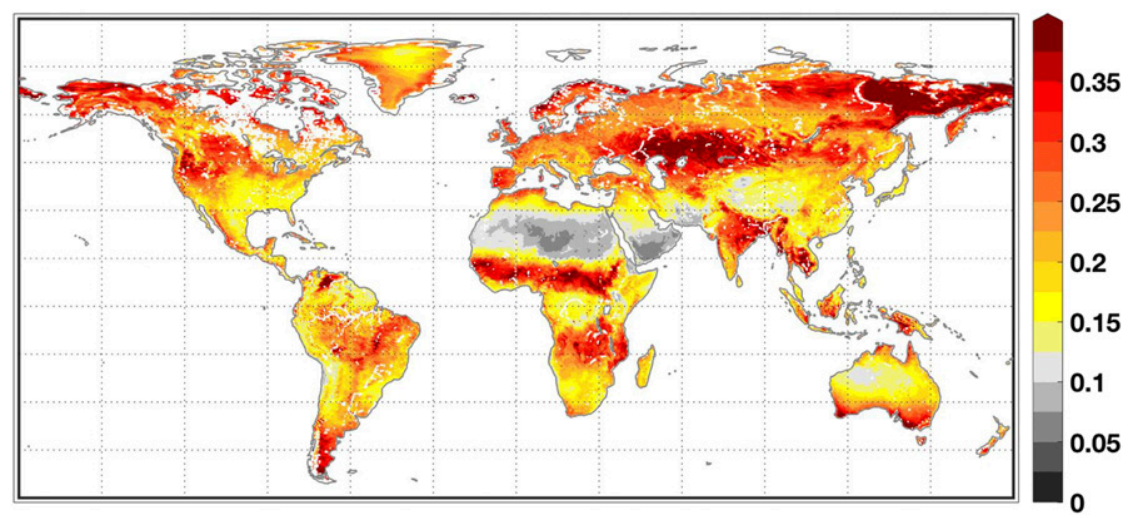

FIG. 6. Spatial distributions of normalized standard deviation (standard deviation divided by mean) of monthly DTR for 2003-17.

shown in Fig. 9 as a function of land-cover types. DTR mean of the Northern Hemisphere also shows a consistent seasonal pattern, larger amplitude in summer than winter for all land-cover types except for tropical/ subtropical evergreen broadleaved forest. Interestingly, DTR of the Southern Hemisphere does not line up with the DTR of the Northern Hemisphere for four landcover types including tropical/subtropical evergreen broadleaved forest, deciduous forest, deciduous woodland, and wooded and nonwooded grasslands. It should be noted that given the high level of humidity in rain forests of tropical regions, it is difficult to detect substantial differences between winter and summer. Duan et al. (2018) noticed rather larger LST discrepancy in MODIS products over grassland vegetation cover sites due to misclassification of the MODIS land-cover type products, resulting to incorrect and unreliable estimation of the surface emissivity. This study uses a static land-cover type and the deciduous forest and deciduous woodland regions were subject to deforestation and
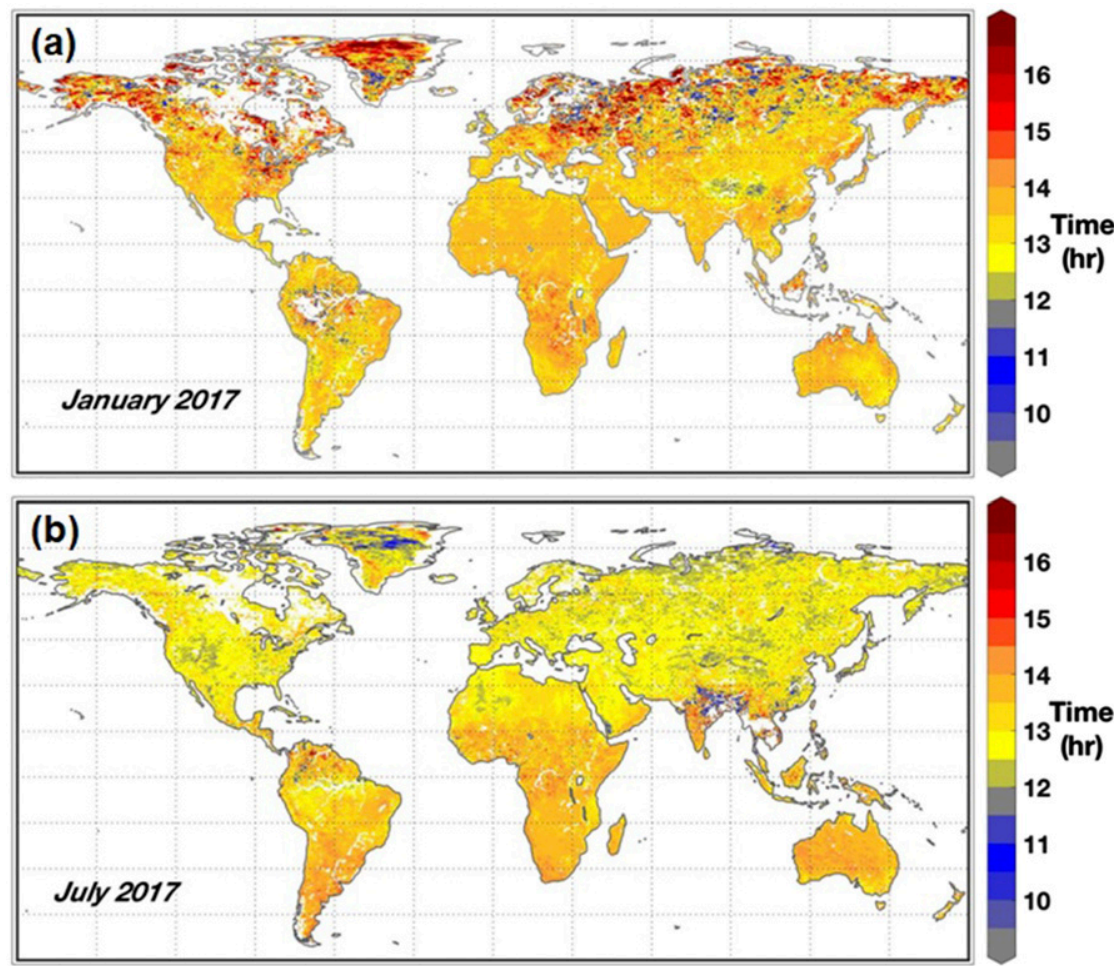

FIG. 7. Spatial distributions of time (local time) of maximum LST for (a) January and (b) July 2017. 


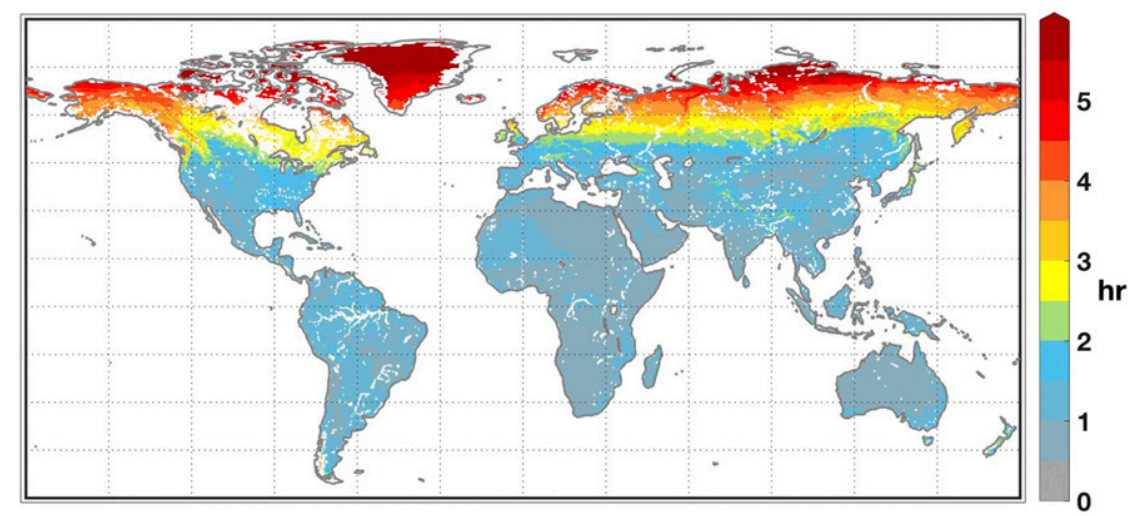

FIG. 8. Spatial distributions of standard deviation in time (local time) of maximum LST for the period of 2003-17.

shift into croplands and grasslands in the recent decades. As mentioned earlier, land-cover alteration changes the reflected solar radiation and latent heat flux leading to extreme DTR (Duveiller et al. 2018; Song et al. 2018). One of the main factors for the notable distinction of DTR over the Northern and Southern Hemispheres is the distribution of land versus ocean. About $39 \%$ of the Northern Hemisphere is land whereas only $19 \%$ of the Southern Hemisphere is covered by land. Rates of heating and cooling are different for land and ocean. Land heats up and cools down much faster relative to the ocean. Given the fact that Northern Hemisphere contains the majority of Earth's landmass, a much larger population (roughly $88 \%$ ), and much more industrialization, pollution variations are more considerable compared to the Southern Hemisphere. The land-cover average of maximum LST hour shows a consistent seasonal pattern for both hemispheres. The maximum LST hour occurs earlier in summer, for example, July in the Northern Hemisphere
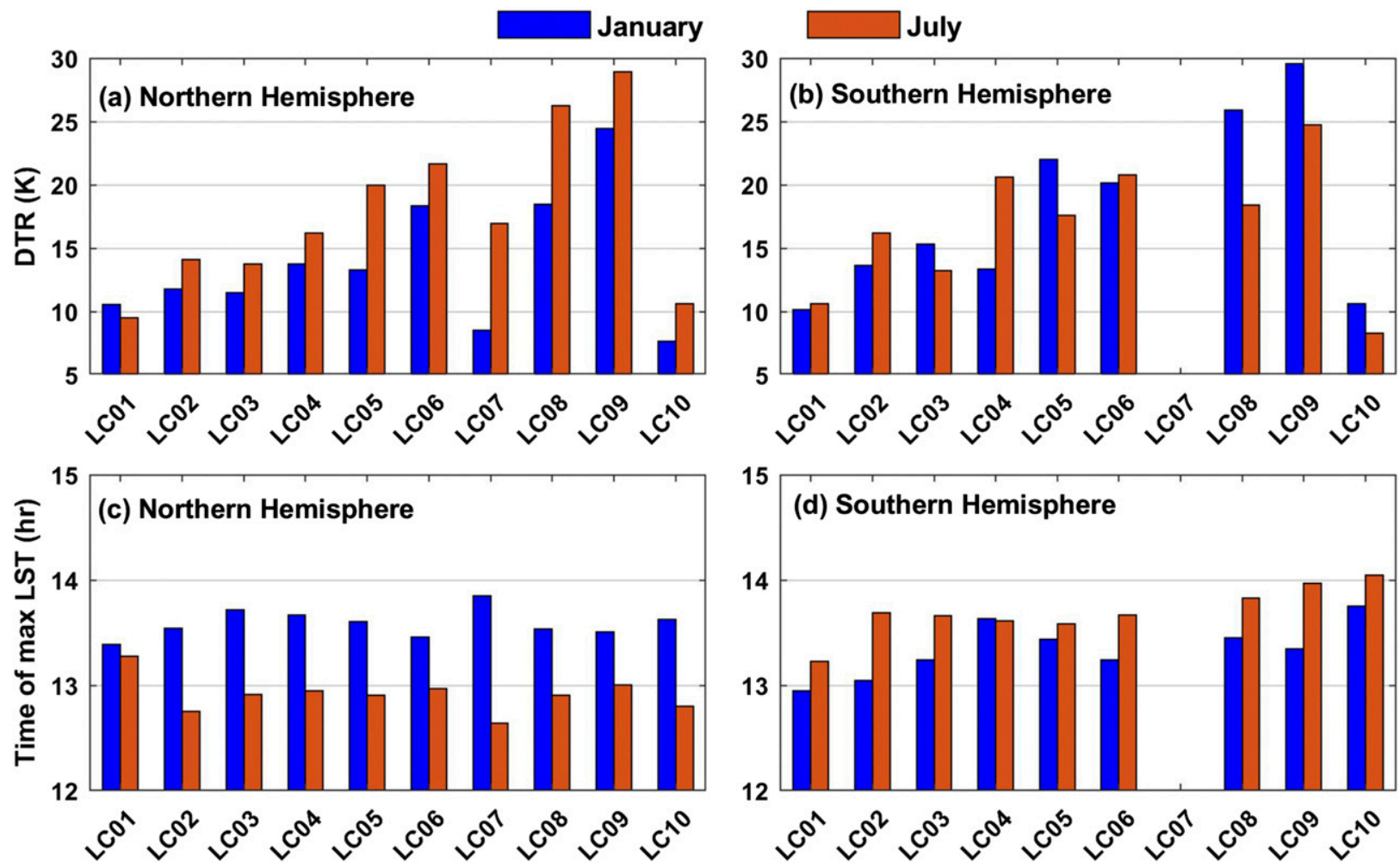

FIG. 9. Mean (a),(b) DTR and (c),(d) time of maximum LST for the (a),(c) Northern and (b),(d) Southern Hemispheres averaged over different land-cover types for January and July. The full names of each land-cover type are given in Table 1. 


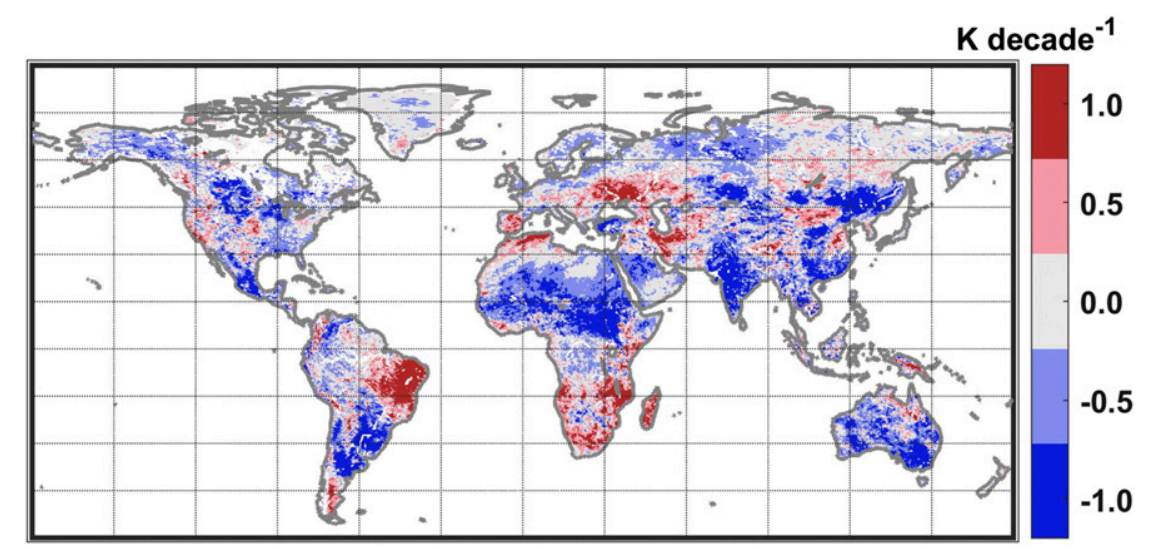

FIG. 10. Spatial distributions of linear trend $\left(\mathrm{K} \mathrm{decade}^{-1}\right)$ in monthly DTR for the period 2003-17.

and January in the Southern Hemisphere for almost all the vegetation classes.

To examine the changes in mean monthly DTR between 2003 and 2017, linear trend in DTR over the global land is presented in Fig. 10. Larger areas show a decline in DTR, which reveals that daily minimum temperature increases at a faster rate than the daily maximum temperature. The Northern Hemisphere showed an overall decrease in DTR of $0.54 \mathrm{~K}$ between 2003 and 2017. However, southern Europe and the Middle East exhibit an increase in DTR during the study period. Deciduous woodland, wooded and nonwooded grassland, and nonvegetated desert land classes show the largest decline. Among them, wooded and nonwooded grassland vegetation type has the largest variations of negative and positive slope values, with the negative parts overcoming the positive parts. The trend fluctuation in grassland cover can be associated with the fact that a majority of existing grasslands used to be forests and woodlands. As previously explained, higher radiative flux leaving the surface is as a consequence of deforestation. However, the balance between shortwave reflected radiation and longwave released radiation can change based on the forest canopy (Duveiller et al. 2018).

Interestingly, the Southern Hemisphere shows variant changes in DTR with land-cover classes. A strong increase of DTR in deciduous woodland of southern Africa, wooded and nonwooded grassland and shrubland of northeastern part of South America, and a strong decrease in DTR for sclerophyllous woodland and forest were observed. Wooded and nonwooded grassland and boreal and xeromorphic shrubland are two land-cover classes having the most variations from highest positive slope value in southern Africa to highest negative in southern Australia. Sclerophyllous woodland and forest of Tasmania and eastern Australia, and nonvegetated deserts of central Australia and Sahara in northern Africa are the two land-cover types showing a consistent negative slope. It should be considered that the assessment was done for a $15-\mathrm{yr}$ period of the MODIS era, which is not adequate for a robust climatic trend analysis. It is also worth noting that the obtained conclusions could be associated with the normalized difference vegetation index, which needs further investigation.

\section{Conclusions}

In this paper, a 15-yr data record of LST Collection 6 from the MODIS sensors was studied. A spline interpolation method was utilized in order to generate half-hourly LST values over the globe land. An initial evaluation of interpolated LST with hourly ground-based observations from the selected 18 USCRN stations over the North America showed a linear correlation of 0.86 and a bias and an RMSE of less than $1 \mathrm{~K}$. In general, the present interpolation method showed promising results in capturing the diurnal variations of LST for different landcover types. The general patterns of LST diurnal variations were well depicted by the interpolated LST for different land-cover types. The interpolated half-hourly LST data were used to calculate two important parameters including DTR as well as timing of the maximum LST hour. The largest DTR of 25-40 K was found over the desert regions, whereas the smallest DTR of less than $5 \mathrm{~K}$ was evident over the high-latitude regions of the Northern Hemisphere. The global desert regions showed smaller variability of monthly mean DTR, and larger areas of the global land exhibited larger variability in DTR between $20 \%$ and $40 \%$ for the 15 -yr period. The time of maximum LST hour moves to about $1 \mathrm{~h}$ earlier during summer as compared to during winter in both hemispheres. However, mean DTR showed distinct seasonal variations as a function of land-cover types. The Northern Hemispheric land showed a decrease in monthly mean DTR by about $0.54 \mathrm{~K}$ between 2003 and 2017. But, the Southern Hemisphere showed variant 
changes in DTR with land-cover classes. However, the assessment was done for a $15-y r$ period and is not adequate for a robust climatic trend analysis.

Furthermore, there are few limitations of this study. The interpolated LST has larger uncertainty over the high-latitude regions because of low DTR, which needs further investigation. The use of a static land-cover type might also contribute to uncertainty in the results because of considerable changes in the global land-cover types during the study period. The diurnal cycle was constructed using cloud-free LST observations in this study, which might lead to uncertainty in the presence of clouds. There are differences in local solar time for the same pixel on different revisit days of the MODIS instruments because of its intrinsic scanning characteristics. Typically, $3-$ $5 \mathrm{~K}$ of LST difference could be introduced because of changes in daytime observations between 1000 and 1200 local solar time from the Terra satellite (Duan et al. 2014b). A temporal normalization scheme needs additional input parameters such as elevation, vegetation type, and normalized difference vegetation index corresponding to LST observations, and the uncertainty of the normalized LST generally becomes larger than the original LST values because of uncertainties of the input parameters. Hence, there is a need to develop a suitable temporal normalization scheme applicable for MODIS global LST products that would essentially improve the accuracy of the interpolated diurnal cycle. Nonetheless, augmentation of a global network of ground-based observations is vital for the comprehensive evaluation of satellite-derived LST estimates.

Acknowledgments. This study was supported by the National Oceanic and Atmospheric AdministrationCooperative Science Center for Earth System Sciences and Remote Sensing Technologies (NOAA-CESSRST) under the Cooperative Agreement Grant NA16SEC4810008, by the NASA under Grant NNH15ZDA001N, and by the Center for Remote Sensing and Earth System Sciences at the New York City College of Technology. The authors thank the editor and anonymous reviewers for their constructive comments. MODIS land surface temperature datasets obtained from the NASA EOSDID LP DAAC (https://lpdaac.usgs.gov/) and USCRN observations from the NOAA's National Climatic Data Center (NCDC) are thankfully acknowledged.

\section{REFERENCES}

Aires, F., C. Prigent, and W. Rossow, 2004: Temporal interpolation of global surface skin temperature diurnal cycle over land under clear and cloudy conditions. J. Geophys. Res., 109, D04313, https://doi.org/10.1029/2003JD003527.
Bell, J. E., and Coauthors, 2013: U.S. Climate Reference Network soil moisture and temperature observations. J. Hydrometeor., 14, 977-988, https://doi.org/10.1175/JHM-D-12-0146.1.

Braganza, K., D. J. Karoly, and J. M. Arblaster, 2004: Diurnal temperature range as an index of global climate change during the twentieth century. Geophys. Res. Lett., 31, L13217, https:// doi.org/10.1029/2004GL019998.

Diamond, H. J., and Coauthors, 2013: U.S. Climate Reference Network after one decade of operations: Status and assessment. Bull. Amer. Meteor. Soc., 94, 485-498, https://doi.org/ 10.1175/BAMS-D-12-00170.1.

Didari, S., H. Norouzi, S. Zand-Parsa, and R. Khanbilvardi, 2017: Estimation of daily minimum land surface air temperature using MODIS data in southern Iran. Theor. Appl. Climatol., 130, 1149-1161, https://doi.org/10.1007/s00704-016-1945-0.

Duan, S.-B., Z.-L. Li, B.-H. Tang, H. Wu, R. Tang, Y. Bi, and G. Zhou, 2014a: Estimation of diurnal cycle of land surface temperature at high temporal and spatial resolution from clear-sky MODIS data. Remote Sens., 6, 3247-3262, https:// doi.org/10.3390/rs6043247.

,,$---\longrightarrow$, and,$- 2014 \mathrm{~b}$ : Generation of a timeconsistent land surface temperature product from MODIS data. Remote Sens. Environ., 140, 339-349, https://doi.org/ 10.1016/j.rse.2013.09.003.

,-- , and P. Leng, 2017: A framework for the retrieval of allweather land surface temperature at a high spatial resolution from polar-orbiting thermal infrared and passive microwave data. Remote Sens. Environ., 195, 107-117, https://doi.org/ 10.1016/j.rse.2017.04.008.

,,-- H. Wu, P. Leng, M. Gao, and C. Wang, 2018: Radiance-based validation of land surface temperature products derived from Collection 6 MODIS thermal infrared data. Int. J. Appl. Earth Obs. Geoinf., 70, 84-92, https://doi.org/ 10.1016/j.jag.2018.04.006.

Duveiller, G., J. Hooker, and A. Cescatti, 2018: The mark of vegetation change on Earth's surface energy balance. Nat. Commun., 9, 679, https://doi.org/10.1038/s41467-017-02810-8.

Ignatov, A., and G. Gutman, 1999: Monthly mean diurnal cycles in surface temperatures over land for global climate studies. J. Climate, 12, 1900-1910, https://doi.org/10.1175/1520-0442(1999) 012<1900:MMDCIS >2.0.CO;2.

Jackson, L. S., and P. M. Forster, 2010: An empirical study of geographic and seasonal variations in diurnal temperature range. J. Climate, 23, 3205-3221, https://doi.org/10.1175/ 2010JCLI3215.1.

Justice, C. O., and Coauthors, 1998: The Moderate Resolution Imaging Spectroradiometer (MODIS): Land remote sensing for global change research. IEEE Trans. Geosci. Remote Sens., 36, 1228-1249, https://doi.org/10.1109/36.701075.

Kilibarda, M., T. Hengl, G. B. M. Heuvelink, B. Graler, E. Pebesma, M. P. Tadic, and B. Bajat, 2014: Spatio-temporal interpolation of daily temperatures for global land areas at $1 \mathrm{~km}$ resolution. J. Geophys. Res. Atmos., 119, 2294-2313, https://doi.org/10.1002/2013JD020803.

Li, Z.-L., S.-H. Tang, H. Wu, H. Ren, G. Yan, Z. Wan, I. F. Trigo, and J. A. Sobrino, 2013: Satellite-derived land surface temperature: Current status and perspectives. Remote Sens. Environ., 131, 14-37, https://doi.org/10.1016/j.rse.2012.12.008.

Lim, Y.-K., M. Cai, E. Kalnay, and L. Zhou, 2008: Impact of vegetation types on surface temperature change. J. Appl. Meteor. Climatol., 47, 411-424, https://doi.org/10.1175/2007JAMC1494.1.

Matthews, E., 1983: Global vegetation and land use: New highresolution data bases for climate studies. J. Climate Appl. 
Meteor., 22, 474-487, https://doi.org/10.1175/1520-0450(1983) $022<0474$ :GVALUN $>2.0 . \mathrm{CO} ; 2$.

Mildrexler, D. J., M. Zhao, W. B. Cohen, S. W. Running, X. P. Song, and M. O. Jones, 2018: Thermal anomalies detect critical global land surface changes. J. Appl. Meteor. Climatol., 57, 391-411, https://doi.org/10.1175/JAMC-D-17-0093.1.

Muster, S., M. Langer, A. Abnizova, K. L. Young, and J. Boike, 2015: Spatio-temporal sensitivity of MODIS land surface temperature anomalies indicates high potential for large-scale land cover change detection in Arctic permafrost landscapes. Remote Sens. Environ., 168, 1-12, https://doi.org/10.1016/j.rse.2015.06.017.

Norouzi, H., W. Rossow, M. Temimi, C. Prigent, M. Azarderakhsh, S. Boukabara, and R. Khanbilvardi, 2012: Using microwave brightness temperature diurnal cycle to improve emissivity retrievals over land. Remote Sens. Environ., 123, 470-482, https://doi.org/10.1016/j.rse.2012.04.015.

- - M. Temimi, A. AghaKouchak, M. Azarderakhsh, R. Khanbilvardi, G. Shields, and K. Tesfagiorgis, 2015: Inferring land surface parameters from the diurnal variability of microwave and infrared temperatures. Phys. Chem. Earth, 8384, 28-35, https://doi.org/10.1016/j.pce.2015.01.007.

Prakash, S., H. Norouzi, M. Azarderakhsh, R. Blake, and K. Tesfagiorgis, 2016: Global land surface emissivity estimation from AMSR2 observations. IEEE Geosci. Remote Sens. Lett., 13, 1270-1274, https://doi.org/10.1109/LGRS.2016.2581140.

,,,---- , and R. Khanbilvardi, 2017: Potential of satellite-based land emissivity estimates for the detection of high-latitude freeze and thaw states. Geophys. Res. Lett., 44, 2336-2342, https://doi.org/10.1002/2017GL072560.

,,,,--- C. Prigent, and R. Khanbilvardi, 2018: Estimation of consistent global microwave land surface emissivity from AMSR-E and AMSR2 observations. J. Appl. Meteor. Climatol., 57, 907-919, https://doi.org/10.1175/JAMCD-17-0213.1.

— , F. Shati, H. Norouzi, and R. Blake, 2019: Observed differences between near-surface air and skin temperatures using satellite and ground-based data. Theor. Appl. Climatol., https://doi.org/10.1007/s00704-018-2623-1, in press.

Prigent, C., W. B. Rossow, and E. Matthews, 1998: Global maps of microwave land emissivities: Potential for land surface characterization. Radio Sci., 33, 745-751, https://doi.org/10.1029/97RS02460.

Rossow, W. B., and R. A. Schiffer, 1999: Advances in understanding cloud from ISCCP. Bull. Amer. Meteor. Soc., 80, 2261-2288, https://doi.org/10.1175/1520-0477(1999)080<2261: AIUCFI $>2.0 . \mathrm{CO} ; 2$.
Ruzmaikin, A., H. H. Aumann, J. Lee, and J. Susskind, 2017: Diurnal cycle variability of surface temperature inferred from AIRS data. J. Geophys. Res. Atmos., 122, $10928-10938$, https://doi.org/10.1002/2016JD026265.

Scheitlin, K. N., and P. G. Dixon, 2010: Diurnal temperature range variability due to land cover and airmass types in the Southeast. J. Appl. Meteor. Climatol., 49, 879-888, https://doi.org/ 10.1175/2009JAMC2322.1.

Shati, F., S. Prakash, H. Norouzi, and R. Blake, 2018: Assessment of differences between near-surface air and soil temperatures for reliable detection of high-latitude freeze and thaw states. Cold Reg. Sci. Technol., 145, 86-92, https://doi.org/10.1016/ j.coldregions.2017.10.007.

Song, Z., and Coauthors, 2018: Global land surface temperature influenced by vegetation cover and $\mathrm{PM}_{2.5}$ from 2001 to 2016 . Remote Sens., 10, 2034, https://doi.org/10.3390/rs10122034.

Thorne, P. W., and Coauthors, 2016: Reassessing changes in diurnal temperature range: Intercomparison and evaluation of existing global data set estimates. J. Geophys. Res. Atmos., 121, 5138-5158, https://doi.org/10.1002/2015JD024584.

Tomlinson, C. J., L. Chapman, J. E. Thornes, and C. Baker, 2011: Remote sensing land surface temperature for meteorology and climatology: A review. Meteor. Appl., 18, 296-306, https:// doi.org/10.1002/met.287.

Wan, Z., 2014: New refinements and validation of the collection6 MODIS land-surface temperature/emissivity product. Remote Sens. Environ., 140, 36-45, https://doi.org/10.1016/ j.rse.2013.08.027.

Weng, Q., and P. Fu, 2014: Modeling diurnal land temperature cycles over Los Angeles using downscaled GOES imagery. ISPRS J. Photogramm. Remote Sens., 97, 78-88, https:// doi.org/10.1016/j.isprsjprs.2014.08.009.

Yu, W., Z. Nan, Z. Wang, H. Chen, T. Wu, and L. Zhao, 2015: An effective interpolation method for MODIS land surface temperature on the Qinghai-Tibet Plateau. IEEE J. Sel. Top. Appl. Earth Obs. Remote Sens., 8, 4539-4550, https://doi.org/ 10.1109/JSTARS.2015.2464094.

Zhan, W., and Coauthors, 2013: Disaggregation of remotely sensed land surface temperature: Literature survey, taxonomy, issues, and caveats. Remote Sens. Environ., 131, 119-139, https:// doi.org/10.1016/j.rse.2012.12.014.

Zhou, J., Y. Chen, X. Zhang, and W. Zhan, 2013: Modelling the diurnal variations of urban heat islands with multi-source satellite data. Int. J. Remote Sens., 34, 7568-7588, https:// doi.org/10.1080/01431161.2013.821576. 